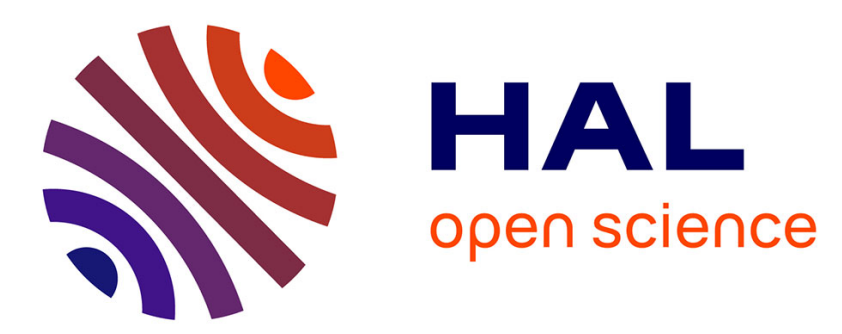

\title{
An innovative system to assist the mobility of people with motor disabilities
}

Faiza Ajmi, Sawssen Ben Abdallah, Sarah Ben Othman, Hayfa Zgaya-Biau, Slim Hammadi

\section{- To cite this version:}

Faiza Ajmi, Sawssen Ben Abdallah, Sarah Ben Othman, Hayfa Zgaya-Biau, Slim Hammadi. An innovative system to assist the mobility of people with motor disabilities. IEEE SMC International coonference on systems, Man and Cybernetics, Oct 2019, Bari, Italy. 10.1109/SMC.2019.8914332 . hal-02439262

\section{HAL Id: hal-02439262 \\ https://hal.science/hal-02439262}

Submitted on 14 Jan 2020

HAL is a multi-disciplinary open access archive for the deposit and dissemination of scientific research documents, whether they are published or not. The documents may come from teaching and research institutions in France or abroad, or from public or private research centers.
L'archive ouverte pluridisciplinaire HAL, est destinée au dépôt et à la diffusion de documents scientifiques de niveau recherche, publiés ou non, émanant des établissements d'enseignement et de recherche français ou étrangers, des laboratoires publics ou privés. 


\title{
An innovative system to assist the mobility of people with motor disabilities
}

\author{
Faiza Ajmi, Sawssen Ben Abdallah, Sarah Ben Othman, Hayfa Zgaya-Biau and Slim Hammadi, \\ Member, IEEE
}

\begin{abstract}
People with motor disabilities require assistance for navigating form one location to another. In order to improve the integration of wheelchair users into their daily life and work, we propose a real time adaptive planning algorithm for routing the user through an obstacle free optimal path. Our application is based on an augmented reality system for the assistance of wheelchair people (ARSAWP) and uses augmented reality (AR) smart glasses. The main goal is to support the development of indoor and outdoor navigation systems devoted to wheelchair users. In this paper we detail the design, the implementation and the evaluation of the proposed application, which was implemented in java for the Android operational system. Two types of database are used (local database and remote database). The information about navigation is displayed on AR glasses which give the user the possibility to interact with the system according to the external environment. The prototype is designed for use within the University of Lille campus.
\end{abstract}

\section{INTRODUCTION}

Despite of the technological leap of the past decade, a large proportion of wheelchair users continues to face enormous complication (challenges) to carry out necessary activities of their dailies. It is obvious that wheelchairs ensure mobility and flexibility of people with motor disabilities, but this is not sufficient. In fact, to provide social inclusiveness and improved quality of life of wheelchair users, it is crucial to give them the means of choice and especially accessibility information such as obstacles. For example, in a scenario within the university, a disabled student (such a wheelchair user) can come across various types of environmental obstacles that can prevent him from participating in many activities (the existence of an elevator or not, an access ramp and washrooms for wheelchair users, etc.). While outdoor navigating, the presence of a dynamic (an under-construction road) or static obstacles (narrow aisles, lighting, bad weather, sidewalk width, etc) can limit the movements of disabled students [1].

In this context, there are several systems based on new information and communication technologies (NICT), which are used to improve motor disabled people inclusion in their surroundings. Among diverse existing technologies, AR is appropriate to make wheelchair users life easier. AR as a technological enabler is becoming more and more popular and usually used in different fields such as transport, warehouses

Faiza Ajmi is a PhD student in Ecole Centrale of Lille, France (e-mail: faiza.ajmi@centralelille.fr).

Sawssen Ben Abdallah is a research engineer in Ecole Centrale of Lille, France (e-mail: sawssen.ben-abdallah@centralelille.fr).

Sarah Ben Othman is a PhD in Ecole Centrale of Lille, France (e-mail: sara.ben-othman@centralelille.fr).

Hayfa Zgaya-Biau is a PhD- HDR in University of Lille, France (e-mail: shayfa.zgaya-biau@univ-lille.fr). management, medicine, etc. Due to technological devices development, increasing trends by using AR among disabled people have been observed [2]. The issue discussed in this manuscript is to improve wheelchair users' mobility and their social inclusion, increasing their independence in daily life. The possible solution is to provide a system designed to help and assist them during their journey while wearing smart glasses using AR technology. In this paper, we use a combination of AR and geological mapping (dynamic and static) as a personalized solution for wheelchair users to navigate independently, freely and carefully from one location to another within the university. We propose a computer architecture ARSAWP supervised by AR smart glasses to guide wheelchair users to the university or to a specified building in the Campus by undertaking a safety and obstacle free route. Our solution uses an innovative real-time pathplanning algorithm providing the shortest path and taking uphill into consideration. This algorithm has been incorporated into the AR glasses system that facilitates obstacle management in terms of reporting obstacles. This navigation assistance supports wheelchair users in their movements giving them the possibility to cooperate and interact with the system. We associate to the information displayed on AR glasses auditory interaction allowing wheelchair users to interact with their environment. This ensures a smooth interaction between the user and his movements information. The goal is to minimize user attention and to facilitate interaction with his environment.

\section{RELATED WORK}

In recent years, AR has already caught its place not only in entertainment industry [3] [4] but also in a context of personal mobility [5] [6] [7]. According to many studies, the number of motor disabled people has been increasing worldwide and there should be solutions able to provide autonomy for wheelchair users. Reason why researchers and healthcare professionals are trying to detach wheelchair users from dependency. In [5] [6], authors expose a design and development of an indoor navigation system based an AR. Then a smart wheelchair with an eye-tracking enabled head mounted display controlled through AR [8]. In the solution proposed in [9] a wheelchair user can communicate with AR application with the help of Radio Frequency Identification (RFID) technologies in order to access the items placed beyond their arm's length. Until now, many researches have

Slim Hammadi is a Full Professor in Ecole Centrale of Lille, France (corresponding author to provide phone: 0033-32033-4547; fax: 003332033-5499; e-mail: slim.hammadi@ centralelille.fr). 
been dedicated to present modern technologies for people with disabilities assistance [10] [11] [12], some works have treated obstacle detection systems [10] [13] and other works [14] [15], describe the use and experiences with public transport accessibility.

All these research works use various optimization approaches, the most prominent are Dijkstra algorithm [16] and graph theory [17]. In [1] authors propose in collaboration with OpenStreetMap (OSM) a routing network generation algorithm for disabled people. This algorithm was tested and evaluated for selected areas in Europe such as Berlin, Riga, and London. Since 2007, personal digital assistant (PDA) has been applied at Pittsburgh University in USA. Researchers [18] have introduced a personalized wheelchair navigation system equipped with a digital map database, a navigation module and a routing module. In this context, the map database should contain many parameters as shown in Table I.

TABLE I. A SUMMARY OF REQUIRED PARAMETERS FOR OUR MAP DATABASE OF AN ITINERARY FOR WHEELCHAIR PEOPLE

\begin{tabular}{|l|l|l|}
\hline \multicolumn{1}{|c|}{ Parameters } & \multicolumn{1}{|c|}{ Description } & Reference \\
\hline Type of street & $\begin{array}{l}\text { Which route can be used for a } \\
\text { wheelchair people? Primary, } \\
\text { secondary or tertiary route. }\end{array}$ & $\begin{array}{l}\text { [1], our } \\
\text { App }\end{array}$ \\
\hline $\begin{array}{l}\text { Type of side- } \\
\text { walk }\end{array}$ & $\begin{array}{l}\text { Sidewalk condition, sidewalk } \\
\text { congestion, sidewalk } \\
\text { geometry (width, surface. }\end{array}$ & $\begin{array}{l}\text { [1], [18], } \\
{[19], \text { our }} \\
\text { app }\end{array}$ \\
\hline $\begin{array}{l}\text { Lighting } \\
\text { (street) }\end{array}$ & Visibility of street. & $\begin{array}{l}{[1],[18],} \\
\text { our app }\end{array}$ \\
\hline $\begin{array}{l}\text { Inside- } \\
\text { Buildings }\end{array}$ & $\begin{array}{l}\text { The buildings accessibility } \\
\text { (door automatic or manual). } \\
{[18], \text { our }} \\
\text { app }\end{array}$ \\
\hline $\begin{array}{l}\text { General } \\
\text { access }\end{array}$ & General access information & $\begin{array}{l}{[1],[18],} \\
{[20], \text { our }} \\
\text { app }\end{array}$ \\
\hline Slope & The slope is steep or flexible & Our app \\
\hline $\begin{array}{l}\text { Free } \\
\text { headroom }\end{array}$ & $\begin{array}{l}\text { The free headroom in the } \\
\text { sidewalk }\end{array}$ & Our app \\
\hline
\end{tabular}

In the works cited above, diverse methods have been presented to liberate wheelchair user from dependency indoor and outdoor. Nevertheless, none of these systems offers a realtime navigation assistance with obstacles management of indoor and outdoor for motor disabled people.

\section{DESIGN AND MODELS}

In the beginning, we did many surveys in order to identify the needs of students with wheelchair. In fact, all wheelchair users are potential users of the application. Nevertheless, knowing that the experimental phase of the prototype takes place within the University of Lille, we have targeted students from this University for the recruitment of participants. We then interviewed 16 students in wheelchairs. We initially wanted to interview 8 students in electric wheelchairs and 8 students in manual wheelchairs. However, we realized that from a perspective of autonomy, the students prefer the use of an electric wheelchair. For this reason, the 16 selected participants are users of an electric wheelchair. The objective is to characterize their actual displacements, their needs and their expectations related to the AR real-time navigation system. In the following section, we describe different diagrams modeling wheelchair users' expectations using SysML language.

\section{A. ARSAWP System Design}

SysML is a powerful language for system engineering able to provide all details needed to make system specification explicit and clear.

The Diagram in Figure 1 gives an overview of the main actors and environmental elements interacting with ARSAWP. At this highest level, all entities (seven entities) and data flow are shown on the context diagram. One represents each interaction or many sequence diagrams.

Figure 1. SysML: Contect Diagram of ARSAWP System

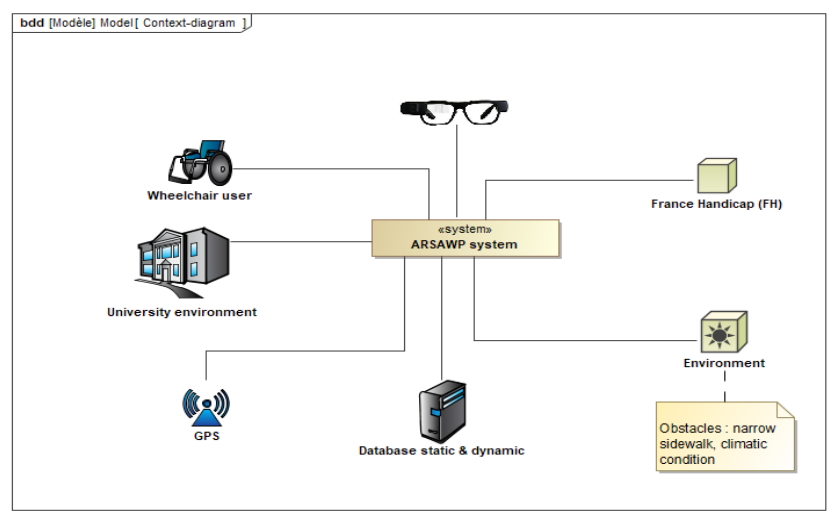

Figure 2. SysML: Requirements Diagram of ARSAWP

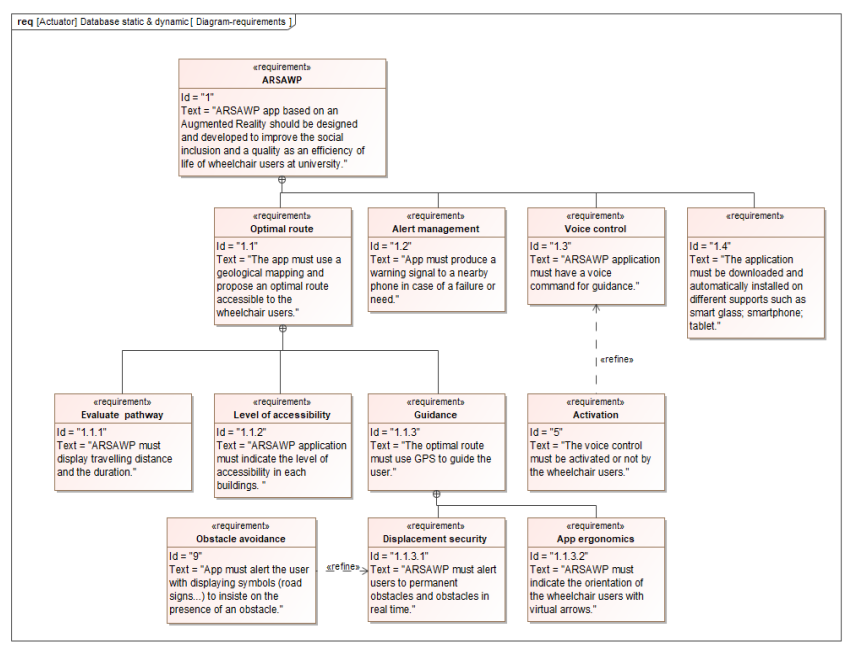

According to the surveys, we built a requirements diagram (Figure 2) verifying the main user requirements that must be respected by our system. This diagram contains two essentials properties: the unique identifier (id ="1" for example) and the text requirement.

In SysML, a use case diagram (Figure 3) can resume details of ARSAWP and user interactions with the system. This diagram determines the relationship between use cases, actors and the system. In this context, ARSAWP system includes two main use cases "Consult profile" and "Route searches". The first use case "Consult profile" allows a wheelchair user to open and parameter his profile. 
Figure 3. SysML: Use case Diagram of ARSAWP system

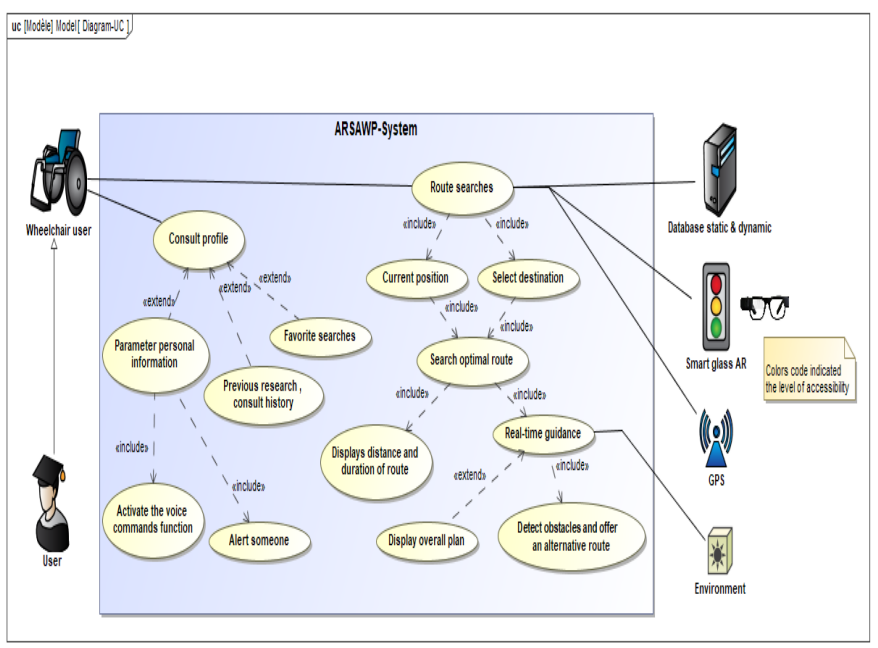

For example: the wheel-chair user can create and save his personal search profiles, so he does not have to re-enter the same search information. The second use case "Route search" explains the different functioning steps of our approach like "current position" and "select destination" to achieve the goal "compute optimal route". In addition, this use case involves the presence of all actors (wheelchair users, static \& dynamic database, AR smart glass, GPS, and environment).

Figure 4. SysML: Sequence Diagram example for use case "Route search"

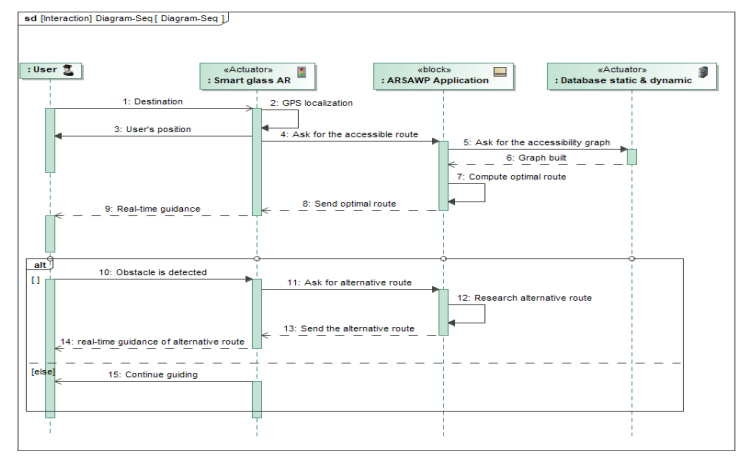

The non-disabled people can also use ARSAWP application. However, a one or many sequences diagram represents each use case in this diagram. An example of a sequence diagram for use case "Route search" is presented in Figure 4. This diagram represents the data flow exchange between the system and different actors. In our example, we have four lifelines (wheelchair user, smart glass AR, ARSAWP application and static \& dynamic database). The wheelchair user initiates the interaction, sends the first message to AR smart glasses, and asks for the accessible chosen route. Then our system computes optimal route and sends the solution to smart glasses that accomplish the realtime guidance. If an obstacle is detected, an alternative optimal route is proposed to continue the guidance.

\section{SOLUTION ARCHITECTURE}

\section{A. Presentation}

Following the design of requirements and block definition diagrams in figure 2 , we are able to design a solution that meets these criteria. With the help of ORA-2 [21] a smart glass that features mobile computing and AR, the ARSAWP gives an augmented touch to accessibility information. It is an innovative way to interact between users and accessibility information in the real world, it gives a secure guidance from a place to another. ARSAWP ensures real-time navigation, provides the shortest path to the destination and redirects the user to an emergency route in case of obstacles are encountered. The solution consists mainly in providing the accessibility information concerning the buildings and makes it possible to guide the user in hand free from a point $A$ to a point $\mathrm{B}$ according to his current position. This process is handled by calculating the shortest path in real time. The user is able to navigate wearing the AR smart glasses and has the possibility to whether activate the voice help or not. ARSAWP is deployed under several platforms that are AR smart glasses, smartphones and tablets.

\section{B. Solution features}

ARSAWP works as an information and data collection system. In fact, it allows to track in real time the actual position of the user allowing him to move in an AR way to a desired point by calculating the shortest path. The user has an idea about the accessibility information of the building to which he is heading, the estimated time and distance to reach the destination. It allows also to report obstacles and to view them in real time on an accessibility map and most importantly it redirects the wheelchair user, when facing obstacles on his path, to an emergency route.

Figure 5. Global architecture

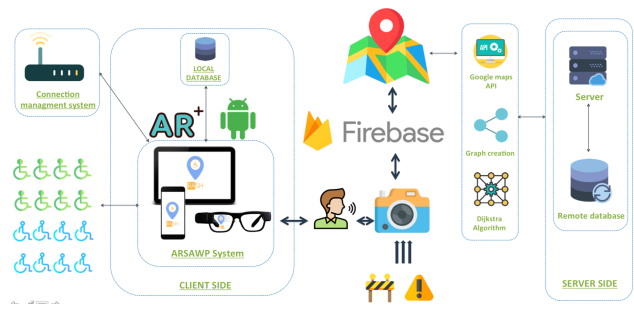

Figure 5 represents the global architecture of ARSAWP system. Wheelchair user connects via his profile to the ARSAWP system. All of these flows and connections are managed by a connection management system.

Wearing the AR smart glasses, wheelchair user is able to choose a place to go to among several destinations according to his current location. But before that, ARSAWP gives him a glimpse of accessibility information concerning the desired destination whether it is accessible, accessible with assistance or not accessible at all. Once the user has chosen his destination, ARSAWP will proceed to creating the accessibility graph towards the desired location in real-time according to the user's GPS coordinates and the area cartography. We propose an innovative and adaptive method 
based on Dijkstra algorithm to calculate the shortest path. In case there's an obstacle blocking the user's way, he can report it. The ARSAWP can then proceed to rerouting to another obstacle-free path. If obstacles are already reported by other users, then obstacles management is handled in terms of notifying wheelchair users of potential obstacles reported that is when a redirection process towards an emergency route is applied by implementing an adaptive algorithm based on Dijkstra algorithm. ARSAWP handles a real-time display of obstacles and paths on a map using google maps API. Applying the proposed method and adaptive algorithm to accessibility graphs and combining it with Google maps API manage this functioning. All these data are stored in a local database and a remote database hosted in a cloud server. Each reported obstacle is recorded in a Firebase, which is a real time database, so that ARSAWP can instantaneously display the obstacles on the map. Our partner in this project APF Lab ${ }^{1}$ is charged of collecting data about the different building and possible itineraries inside Lille University, verifying and deleting malicious reports and temporary obstacles if they no more exist.

\section{Proposed method}

The proposed method aims to guide impaired students through the various buildings within the university from their current location to the desired destination. If they need assistance the system will notify if, for instance, the entrance door needs assistance and the user can take it into account.

Our method performs an optimal path on a university layout that assumes many buildings and paths. If an obstacle is identified during the navigation through the suggested accessible path, the proposed method takes into account the obstacle parameter and reroutes the user through a new optimal path. Our solution needs as input to process the path finding an accessibility graph related to the university layout, user's current location, user's desired destination, distance and time estimated, and the list of obstacles identified.

\section{Methodology implementation}

The proposed algorithm (algorithm 1) aims at guiding the wheelchair users at the various places of university. our algorithm is based on four different matrixes, these matrixes are defined in table II. The algorithm is distinguished by its adaptive method that can adapt in real time to the needs of people with disabilities.

TABLE II. ALGORITHMS INTEGRATED INTO AR GLASS

\begin{tabular}{|c|c|c|c|}
\hline \multicolumn{4}{|c|}{ DECISION MATRICES } \\
\hline $\begin{array}{l}\text { WEIGHT } \\
\text { MATRIX }\end{array}$ & $\begin{array}{l}\text { NORMALIZED } \\
\text { WEIGHT MATRIX }\end{array}$ & $\begin{array}{l}\text { UPHILL } \\
\text { MATRIX }\end{array}$ & $\begin{array}{l}\text { OBSTACLE } \\
\text { MATRIX }\end{array}$ \\
\hline $\begin{array}{c}\text { Let } \mathbf{W} \text { be the } \\
\text { weight matrix } \\
\text { corresponding to } \\
\text { the graph where } \\
\mathbf{W}[\mathbf{i}, \mathbf{j}]=\text { distance } \\
\text { from node } \mathrm{i} \text { to node } \\
\mathrm{j} \\
\mathbf{W}[\mathbf{i}, \mathbf{j}]=\infty,(\mathrm{i}, \mathrm{j}) \text { is } \\
\text { not an edge in the } \\
\text { graph or } \mathrm{i}=\mathrm{j}\end{array}$ & $\begin{array}{c}\text { Let } \boldsymbol{N W} \text { be the } \\
\text { normalized weight } \\
\text { (dividing all the weight } \\
\text { values other than } \infty \text { in the } \\
\text { weight matrix by the } \\
\text { maximum weight } \boldsymbol{m} \boldsymbol{w} \text { ) } \\
\boldsymbol{N} \boldsymbol{W}[\boldsymbol{i}, \boldsymbol{j}]=\boldsymbol{W}[\boldsymbol{i}, \boldsymbol{j}] / \boldsymbol{m} \boldsymbol{w}\end{array}$ & $\begin{array}{l}\text { Let } \boldsymbol{U P} \text { be the } \\
\text { uphill matrix } \\
\boldsymbol{U P}[\boldsymbol{i}, \boldsymbol{j}]=\boldsymbol{0 . 5} \text {, if } \\
\text { the is an uphill } \\
\boldsymbol{U P}[\boldsymbol{i}, \boldsymbol{j}]=\boldsymbol{0} \\
\text { otherwise }\end{array}$ & $\begin{array}{c}\text { Let } \boldsymbol{O} \text { be the } \\
\text { obstacle matrix } \\
\boldsymbol{O}[\boldsymbol{i}, \boldsymbol{j}]=1 \text {, if } \\
\text { there's an } \\
\text { obstacle } \\
\boldsymbol{O}[\boldsymbol{i}, \boldsymbol{j}]=\boldsymbol{0}, \\
\text { otherwise }\end{array}$ \\
\hline
\end{tabular}

${ }^{1}$ https://www.apf-francehandicap.org/handicap-et-nouvelles-technologies-9730

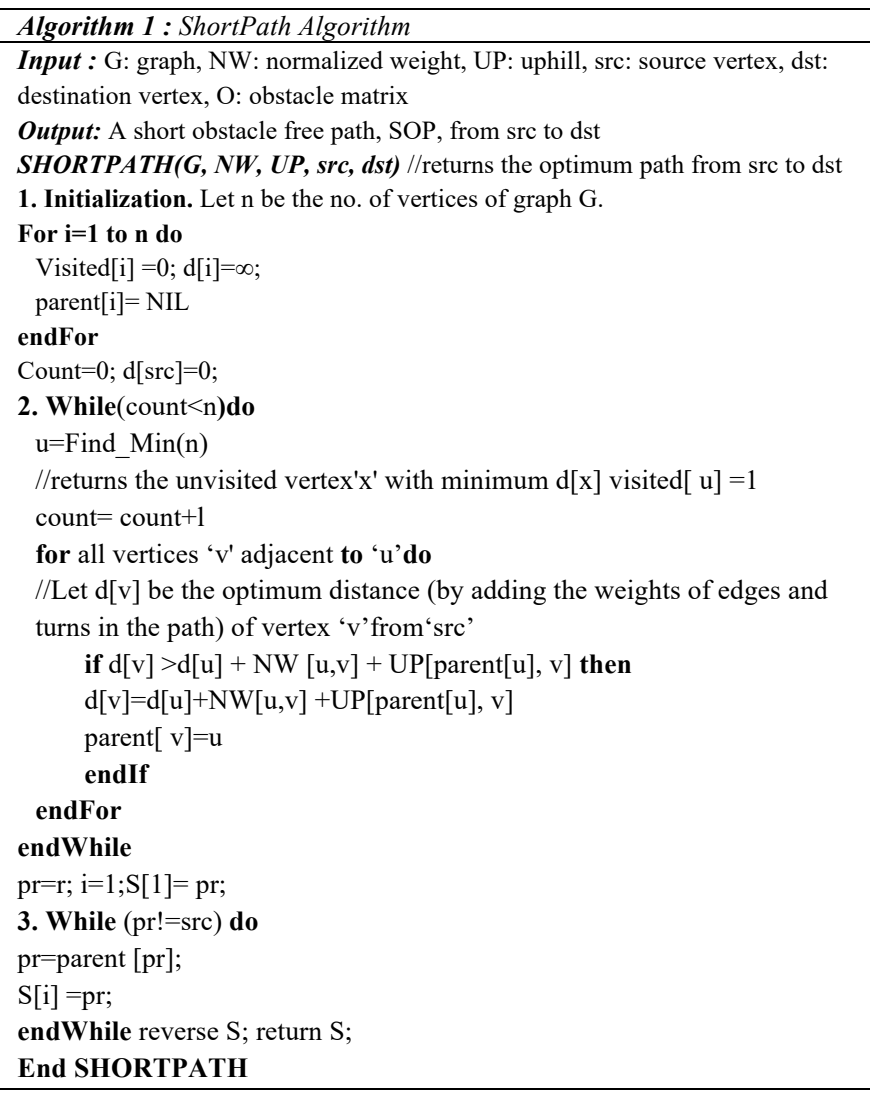

In cases where an obstacle is detected during the navigation through the suggested path, the algorithm reroutes the wheelchair users to his destination through a novel optimal path thanks to its adaptive approach (algorithm 2).

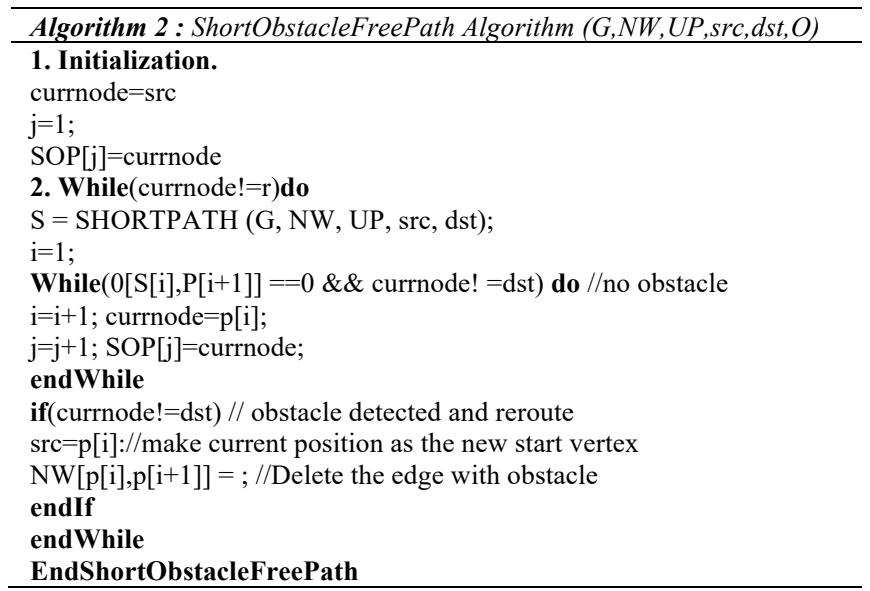

\section{SimUlation AND RESUlts}

Various tests were performed for different scenarios (getting accessibility information, a route with obstacles and accessible with assistance) in Lille University in the north of France. We considered students using wheelchair to test the developed prototype. 
Figure 6. Accessibility graph

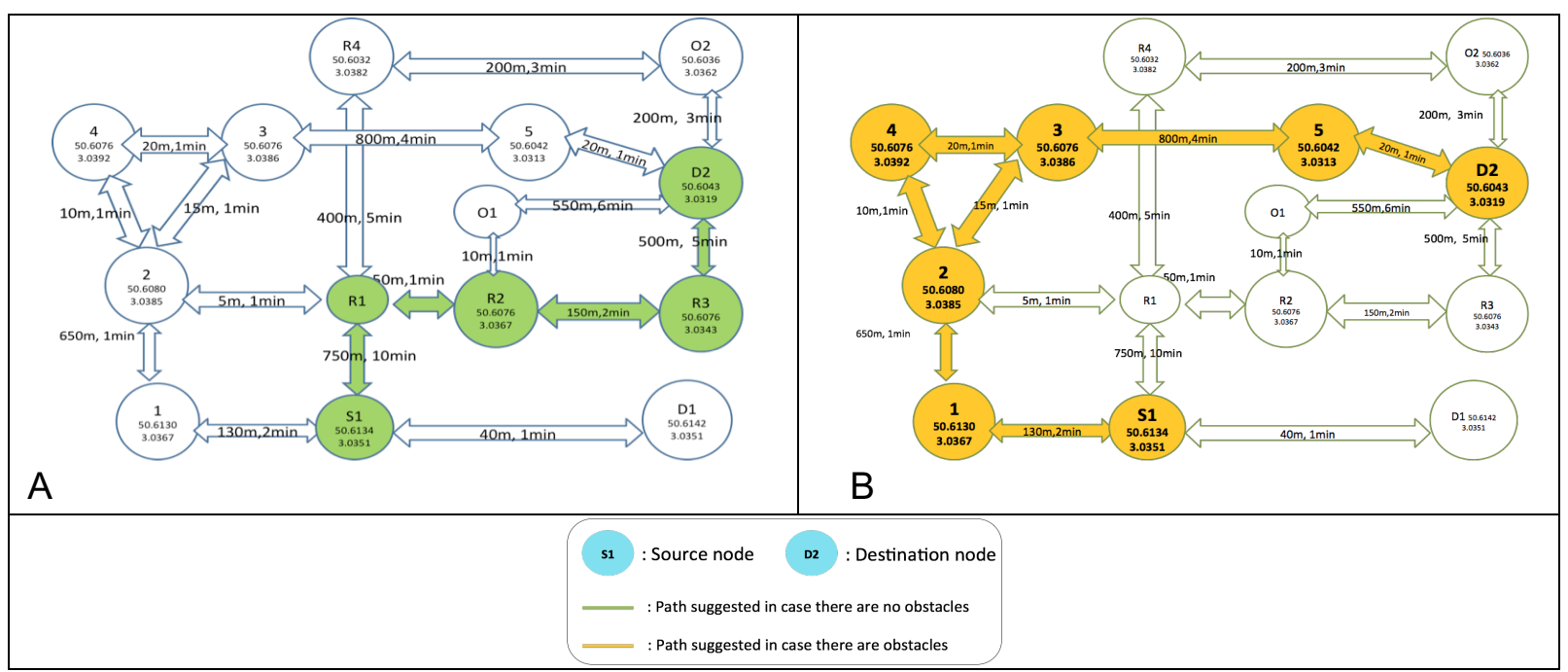

Figure 6 describes the algorithm behavior that has been implemented by taking Lille university accessibility graph to start from Lille university residence to the main building in the campus. ShortPath Algorithm ensures the safest and shortest route for students using wheelchair and re-routes them to their desired destination in case of obstacles.

Considering the graph shown in figure 6. A, node $\mathrm{S} 1$ is the user's current position and node D2 is the destination. There are several ways to reach $\mathrm{D} 2$. The proposed algorithm gives the user the most suitable path considering his needs. Whereas in case there are obstacles a new free-obstacle path is proposed as shown in figure 6.B. For example, an obstacle has been determined at the node (R1) in the optimal path (S1, R1, R2, R3, D2). So, the brink (R1) will be deleted and the algorithm is called anew to find a new path from node S1 to node D2. As a result, the presented algorithm redirects the wheelchair users to the new path (S1, 1, 2, 3, 5, D2).

In this simulation, $N$ denotes the total number of nodes. $N i$ is the building at node $i$ and $C$ is the final node (destination).

- $d_{i j}$ is the distance between node $i$ and node $j, d_{i j}=\infty$ if the path does not exist between $i$ and $j$.

- $i=0 . . N$ is the index of predecessor node.

- $j=0 . . N$ is the index of successor node.

- $X_{i j}=1$ if the path from node $i$ to node $j$ is chosen, 0 otherwise.

- $t_{i j}$ is the time spent to go from node $i$ to node $j$.

The objective function is to minimize F. F is calculated as follows:

$$
F=\sum_{i \in N} \quad \sum_{j \in N} d_{i j} * t_{i j}^{*} X_{i j}
$$

The proposed mathematical model was designed while also respecting different constraints set by the user:
- $\sum_{\mathrm{j} \in \mathrm{N}} X 0 j=1$; makes sure that each node is visited only once.

- $\sum_{\mathrm{i} \in \mathrm{N}} X i c=1 ;$ makes sure that wheelchair user goes to a destination $c, c \in N$.

- $\sum_{\mathrm{i} \in \mathrm{N}} X i u+\sum_{\mathrm{j} \in \mathrm{N}} X u j=2 \quad \forall u \in N$; provides the continuity of the route by the wheelchair users, the visited node must imperatively be left.

\section{A. User scenario 1: Accessibility information of desired destination}

The first steps that the user has to undertake within ARSAWP are displaying buildings around him and showing accessibility information of a specific building. They are shown in the form of green markers on the map and as the user chooses a desired destination a small window will be shown and he will be able to view the most relevant accessibility information.

Figure 7. Accessibility informations

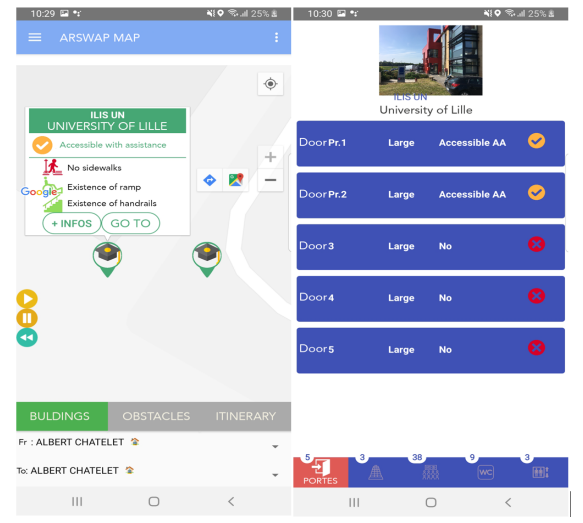

Figure 7 shows that ARSAWP provides detailed accessibility information in terms of dedicated equipment that are provided 
such as large doors, equipped toilets and elevators. In order to give the user a hint about accessibility level a code of colors has been set: Green for accessible, Orange for Assistance needed and Red for not accessible.

\section{B. User scenario 2: Itinerary showing and navigation without obstacles}

Figure 8 shows that once the user has chosen his destination, he can display an overview of his itinerary showing the distance and time estimated to reach the desired destination.

This itinerary is calculated after ARSAWP has proceeded to the accessibility paths creation and path optimization using the proposed algorithm that is providing the shortest path between the user's current position and his destination.

Figure 8. Itinerary showing and navigation without obstacles

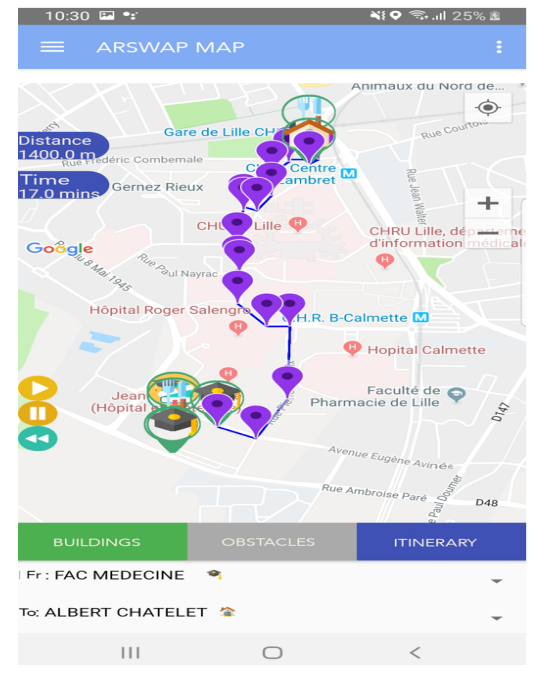

\section{User scenario 3: Navigation with obstacles}

Sometimes users chose an itinerary where other users have reported obstacles, in fact ARSAWP handles obstacles management and notify the user of their existence by ensuring a redirection towards an emergency route calculated by the proposed algorithm as shown in Figure 9. In this figure, the purple pines indicate the path before the obstacle is detected, and the orange pines indicate the changes in the path avoiding obstacles.

Figure 9. Redirection and obstacles managment

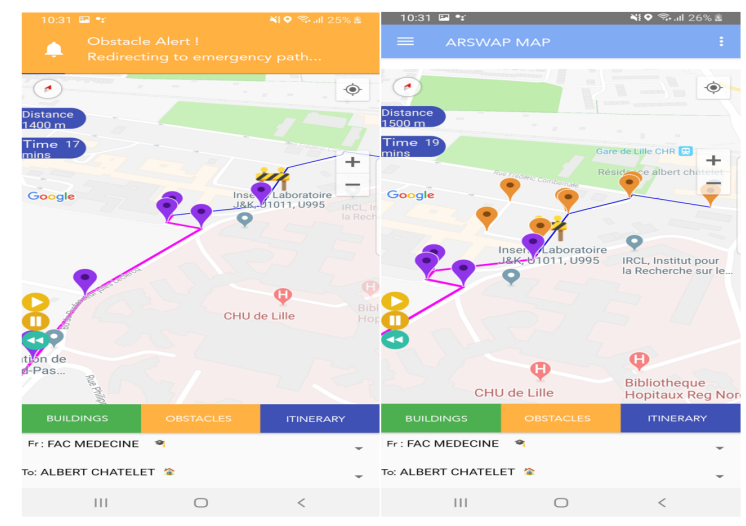

ARSAWP shows in real-time obstacles and paths on the map that are saved in Firebase, which is a real time database so that other users using the application can see display in realtime what's happening.

AR glasses allow users to have their hands free and to be able to interact with the system via voice command. The routes shown in Figure 7, 8 and 9 are displayed and are updated in real time on AR glasses worn by the disabled students.

\section{Wheelchair users' feedback and comments}

TABLE III. FEEDBACKS AND COMMENTS

\begin{tabular}{|c|c|c|c|}
\hline Users & User 1 & User 2 & User 3 \\
\hline $\begin{array}{l}\text { Feedback } \\
\& \\
\text { comments }\end{array}$ & $\begin{array}{l}\text {-Accessibility } \\
\text { information is } \\
\text { clear } \\
\text {-Easy to use } \\
\text {-Friendly user } \\
\text { interface } \\
\text {-Innovative idea } \\
\text {-Appreciates that } \\
\text { time and distance } \\
\text { change in real-time } \\
\text { when changing the } \\
\text { itinerary to an } \\
\text { alternative one. }\end{array}$ & $\begin{array}{l}\text {-Needs more } \\
\text { specification in } \\
\text { accessibility } \\
\text { levels } \\
\text {-Appreciates } \\
\text { vocal command } \\
\text { interaction } \\
\text {-Useful } \\
\text { information about } \\
\text { the itinerary } \\
\text { - Smooth and } \\
\text { easy guidance }\end{array}$ & $\begin{array}{l}\text { - Wants to add a } \\
\text { browser to } \\
\text { select the } \\
\text { desired } \\
\text { destination } \\
\text { - Proposes to } \\
\text { specify the } \\
\text { obstacle type } \\
\text { when reporting } \\
\text { it } \\
\text { - Appreciates } \\
\text { accessibility } \\
\text { information }\end{array}$ \\
\hline $\begin{array}{l}\text { Video } \\
\text { Link }\end{array}$ & \multicolumn{3}{|c|}{$\frac{\text { https://drive.google.com/open?id=1NOe- }}{\text { YMv0 t3Au23B0ogKibBdlqww3vml }}$} \\
\hline
\end{tabular}

\section{Discussion}

The main purpose of ARSAWP system is to provide accessibility information to wheelchair users since they are not within the reach of public use and difficult to be found.

Our solution ensures that the user is getting the right and precise information that he needs and allow him easy and smooth interactions to avoid any discomfort. In fact, we had many interesting and deep discussions with users presenting physical and mobility impairments and they clearly expressed their expectations from this kind of system. Indeed, by using AR technology and the proposed algorithm, we provide the main necessary accessibility information concerning the destination with the possibility to notify the users of an obstructed route and redirect them to an emergency path to avoid any inconvenience. Our ARSAWP system provides accessibility information and makes the real time navigation hands-free. We want to make sure that system is available not only for wheelchair users but for all people who present any other kind of disabilities. The system will provide accessibility information according to the user's profile and to the type of his disability. It will also ensure guidance according to the energy that will costs the user. What is important is that the next steps to take are enhancing the developed system to meet expectations of wheelchair users whom we interviewed.

\section{CONCLUSION}

A new way of mobility assistance algorithm dedicated to 
people with mobility impairments is proposed in this paper. The main characteristic of the algorithm is the minimization of distance and time needed to reach the destination while managing the dynamic and static obstacles detected in the itinerary proposed, which is one of the preferences of wheelchair users. The result of this proposed algorithm has been tested validated in collaboration with APF-LAB ( https://www.apf-francehandicap.org/handicap-et-nouvellestechnologies-9730).

\section{ACKNOWLEDGMENT}

This work is a part of the project "Investing in Digital Technology to Develop E-Inclusion" which aims to make IT tools accessible to people with disabilities and is supported and financed by European Regional Development Fund (http://www.pourlasolidarite.eu/fr/project/indi-adapter-lenumerique-aux-handicaps-et-investir-le-inclusion).

\section{REFERENCES}

[1] P. Neis et D. Zielstra, « Generation of a tailored routing network for disabled people based on collaboratively collected geodata ", Applied Geography, vol. 47, p. 70-77, févr. 2014.

[2] S. A. Malik, L. M. Abdullah, M. Mahmud, et M. Azuddin, « Mobile applications using augmented reality to support older people », in 2013 International Conference on Research and Innovation in Information Systems (ICRIIS), 2013, p. 374-379.

[3] Á. Zsila et al., « An empirical study on the motivations underlying augmented reality games: The case of Pokémon Go during and after Pokémon fever », Personality and Individual Differences, vol. 133, p. 56-66, oct. 2018.

[4] F. Z. Eishita et K. G. Stanley, « The impact on player experience in augmented reality outdoor games of different noise models », Entertainment Computing, vol. 27, p. 137-149, août 2018.

[5] U. Rehman et S. Cao, « Augmented Reality-Based Indoor Navigation Using Google Glass as a Wearable Head-Mounted Display », in 2015 IEEE International Conference on Systems, Man, and Cybernetics, 2015, p. 1452-1457.

[6] U. Rehman et S. Cao, « Augmented-Reality-Based Indoor Navigation: A Comparative Analysis of Handheld Devices Versus Google Glass », IEEE Transactions on Human-Machine Systems, vol. $47, \mathrm{n}^{\circ} 1$, p. 140-151, févr. 2017.

[7] L. C. de Oliveira et al., « Mobile Augmented Reality enhances indoor navigation for wheelchair users ", Research on Biomedical Engineering, vol. 32, $\mathrm{n}^{\circ}$ 2, p. 111-122, juin 2016.

[8] R. Chacón-Quesada et Y. Demiris, « Augmented Reality Control of Smart Wheelchair Using Eye-Gaze-Enabled Selection of Affordances ».

[9] Z. Rashid, J. Melià-Seguí, R. Pous, et E. Peig, « Using Augmented Reality and Internet of Things to improve accessibility of people with motor disabilities in the context of Smart Cities ", Future Generation Computer Systems, vol. 76, p. 248-261, nov. 2017.

[10] E. Y. Kim, « Wheelchair Navigation System for Disabled and Elderly People », Sensors, vol. 16, n ${ }^{\circ} 11$, p. 1806, nov. 2016.

[11] J. Elakkiya et K. S. Gayathri, «Progressive assessment system for dementia care through smart home », in 2017 International Conference on Algorithms, Methodology, Models and Applications in Emerging Technologies (ICAMMAET), 2017, p. 1-5.

[12] T. Mizumoto, A. Fornaser, H. Suwa, K. Yasumoto, et M. D. Cecco, « Kinect-Based Micro-Behavior Sensing System for Learning the Smart Assistance with Human Subjects Inside Their Homes », in 2018 Workshop on Metrology for Industry 4.0 and IoT, 2018, p. 1-6.

[13] A. Hüntemann, E. Demeester, E. V. Poorten, H. V. Brussel, et J. D. Schutter, «Probabilistic approach to recognize local navigation plans by fusing past driving information with a personalized user model », in 2013 IEEE International Conference on Robotics and Automation, 2013, p. 4376-4383.
[14] R. Velho, « Transport accessibility for wheelchair users: A qualitative analysis of inclusion and health », International Journal of Transportation Science and Technology, mai 2018.

[15] J. L. Bezyak, S. A. Sabella, et R. H. Gattis, « Public Transportation: An Investigation of Barriers for People With Disabilities », Journal of Disability Policy Studies, vol. 28, n $\mathrm{n}^{\circ}$ 1, p. 52-60, juin 2017.

[16] J. L. Galán-García, G. Aguilera-Venegas, M. Á. Galán-García, et P. Rodríguez-Cielos, «A new Probabilistic Extension of Dijkstra's Algorithm to simulate more realistic traffic flow in a smart city ", Applied Mathematics and Computation, vol. 267, p. 780-789, sept. 2015.

[17] M. Dehmer, F. Emmert-Streib, et Y. Shi, «Quantitative Graph Theory: A new branch of graph theory and network science », Information Sciences, vol. 418-419, p. 575-580, déc. 2017.

[18] D. Ding et al., « Design Considerations for a Personalized Wheelchair Navigation System », in 2007 29th Annual International Conference of the IEEE Engineering in Medicine and Biology Society, 2007, p. 4790-4793.

[19] H. Matthews, L. Beale, P. Picton, et D. Briggs, « Modelling Access with GIS in Urban Systems (MAGUS): Capturing the Experiences of Wheelchair Users », Area, vol. 35, n 1, p. 34-45, 2003.

[20] A. D. Sobek et H. J. Miller, « U-Access: a web-based system for routing pedestrians of differing abilities ", J Geograph Syst, vol. 8, $\mathrm{n}^{0}$ 3, p. 269-287, sept. 2006.

[21] N. Thapar et al., « A pilot study of functional access to public buildings and facilities for persons with impairments », Disability and Rehabilitation, vol. 26, $\mathrm{n}^{\circ}$ 5, p. 280-289, mars 2004. 